\title{
A novel implantable device for the treatment of obstructive sleep apnea: clinical safety and feasibility
}

This article was published in the following Dove Press journal:

Nature and Science of Sleep

4 May 2016

Number of times this article has been viewed

\author{
Vaclav Pavelec ${ }^{1,2}$ \\ Brian W Rotenberg ${ }^{3}$ \\ Joachim T Maurer ${ }^{4}$ \\ Edward Gillis ${ }^{5}$ \\ Thomas Verse ${ }^{6}$
}

'LENTE Clinic, ${ }^{2}$ Faculty of Health Studies of West Bohemia University, Plzeň, Czech Republic; ${ }^{3}$ Department of Otolaryngology, Head and Neck Surgery, Western University, London, ON, Canada; ${ }^{4}$ Department of Otorhinolaryngology, Head and Neck Surgery, University Medicine Mannheim, Mannheim, Germany; ${ }^{5}$ ReVENT Medical, Inc., Newark, CA, USA; ${ }^{6}$ Department of Otorhinolaryngology, Head and Neck Surgery, Asklepios Klinikum Harburg. Hamburg, Germany
Correspondence: Edward Gillis

ReVENT Medical, Inc., Suite 350, 39899

Balentine Drive, Newark, CA 94560, USA

Tel +I 5102790700

Email ed@reventmedical.com
Objective: Many cases of obstructive sleep apnea (OSA) involve collapse of the tongue base and soft palate during sleep, causing occlusion of the upper airway and leading to oxygen desaturation. Existing therapies can be effective, but they are plagued by patient adherence issues and the invasiveness of surgical approaches. A new, minimally invasive implant for OSA has been developed, which is elastic and contracts a few weeks after deployment, stabilizing the surrounding soft tissue. The device has had good outcomes in preclinical testing; this report describes the preliminary feasibility and safety of its implementation in humans.

Patients and methods: A prospective, multicenter, single-arm feasibility study was conducted. Subjects were adults with moderate-to-severe OSA who had previously failed or refused conventional continuous positive airway pressure treatment. Intraoperative feasibility data, postoperative pain, and safety information were collected for a 30-day postoperative period.

Results: Forty subjects participated (37 men, three women; average age of 46.1 years); each received two tongue-base implants and two soft-palate implants. Surgical procedure time averaged 43 minutes. Postsurgical pain resolved readily in most cases; at 30 days post implantation, $<20 \%$ of subjects reported pain, which averaged less than two out of ten. Adverse events were generally the mild and expected sequelae of a surgical procedure with general anesthesia and intraoral manipulation. The device was well tolerated. Implant extrusions were reported with soft-palate implants $(n=12)$, while tongue-base implants required few revisions $(n=2)$. Quantitative and qualitative sleep effectiveness outcomes (including full-night polysomnographic and quality-of-life measures) will be presented in a subsequent report.

Conclusion: Implantation of the device was feasible. Although a relatively high rate of extrusions occurred in the now-discontinued palate implants, tongue-base implants were largely stable and well tolerated. The minimally invasive and maintenance-free implant may provide a new alternative to higher morbidity surgical procedures.

Keywords: obstructive sleep apnea, implantable device, surgical treatment, breathing, sleep, tongue base

\section{Introduction}

Sleep disorders have been described in the medical literature since the 19 th century. ${ }^{1}$ Obstructive sleep apnea (OSA) is a treatable but markedly underdiagnosed condition of frequent breathing pauses during sleep. OSA is defined by recurrent episodes of apnea (complete cessation of airflow) or hypopnea associated with persistent respiratory effort during sleep. ${ }^{2}$ OSA is associated with a number of significant health consequences, such as cardiovascular disease, atherosclerosis, hypertension, heart failure, arrhythmias, stroke, diabetes, headaches, depression and impaired motor/visual skills, accidents, 
and all-cause mortality. ${ }^{1,3-12}$ The US/European prevalence of OSA is $2 \%-11 \%$, and its health care costs are estimated at \$34 billion. $5,13,14$

One of the more common etiologies of OSA is the collapse of the soft palate and/or tongue base during sleep. ${ }^{15}$ Continuous positive airway pressure (CPAP) provides a "pneumatic splint" that holds the airway open and remains the standard of care, reducing cardiovascular risk. ${ }^{6,7,16}$ The effectiveness of CPAP, although high with perfect usage, is less under typical conditions because up to $40 \%$ of patients are unable to tolerate it or are nonadherent. ${ }^{17-19}$ The effectiveness of oral appliances for mandibular advancement is similar to that of CPAP in the short term, but adherence rates likewise decrease over time. ${ }^{20,21}$ Surgical options may be investigated upon failure or intolerance to these interventions, as most do not require daily equipment use and therefore do not depend on patient adherence. ${ }^{22}$ Surgeons aim to improve upper airway patency by widening the airway, removing anatomical obstruction, stiffening the pharyngeal wall, and/or increasing muscle tone without compromising normal functions such as breathing, speaking, and swallowing.

A large variety of surgical options exist, including reduction of nasal obstruction, oropharyngeal enlargement (uvulopalatopharyngoplasty or modifications with/without tonsillectomy, expansion sphincter pharyngoplasty, or transpalatal advancement pharyngoplasty), hypopharyngeal dilation, maxillomandibular advancement, rigid tongue implants, tongue suture techniques and tongue/hyoid suspension techniques, and hypoglossal nerve stimulation. ${ }^{22-28}$ Effectiveness of these surgical approaches ranges from $30 \%$ to $66 \%$, depending on technique, although definitive assessment is difficult because the field of published literature in this interventional area is primarily composed of small cohort studies of varying methodology. ${ }^{29-33}$ Radio frequency tissue ablation is gaining popularity as an OSA treatment, and a recent meta-analysis concluded its effectiveness for base-of-tongue procedures. ${ }^{34}$ However, randomized, controlled trials have not demonstrated consistent evidence for the effectiveness of surgical and implant approaches, and a systematic review on surgery for sleep apnea concluded that the overall significant benefit of surgery has not been demonstrated. ${ }^{35,36}$

Regardless of their clinical effectiveness, all of these interventions - like any surgical approach - carry morbidity risks including infection in addition to significant recovery time. In OSA surgeries, there is a perioperative complication rate of $\sim 7 \%$, including serious ones such as hemorrhage, edema, and upper-airway obstruction, which can carry legal implications. ${ }^{37,38}$ In addition, approximately half of the patients report long-term problems with dysphagia, voice changes, and a foreign-body sensation in the throat. ${ }^{35}$ Swallowing dysfunction has a reported incidence as high as $87 \%$ in the early postoperative period, resolving to $\sim 12 \%$ (and generally of mild severity) after 6 months. ${ }^{39,40}$ Moreover, the applicability of OSA surgeries is limited by the technical difficulty of performing the procedures and their considerable cost.

Thus, there remains a clear need for an OSA solution that can address issues of patient adherence and provide a significant and lasting effect with minimal disruption of tissue. To be effective, an OSA treatment must address all potential sources of upper-airway obstruction (principally collapse of the soft palate and/or tongue base during sleep) or be compatible with other OSA interventions to allow utilization in multilevel disease and have reproducible outcomes for a broad user base with minimal training. Furthermore, the design of any implanted device must incorporate materials with long-term biocompatibility and lifetime stability, be easy to implant and remove (if desired), possess sufficient strength to provide soft tissue support but have sufficient elasticity to allow for normal speech and swallowing without any awareness of the device, use well-accepted and readily available biomaterials, and be easily and reproducibly manufactured at a reasonable cost.

A novel device for the treatment of OSA has been developed in accordance with these aims and was tested in laboratory conditions and in animal models. Results indicated that it is biocompatible and well tolerated. ${ }^{41}$ This report describes the feasibility and acute safety data of the first trial of this novel device in human subjects; clinical and patient-reported effectiveness outcomes will be presented in a forthcoming report.

\section{Patients and methods Study design}

This prospective, multicenter, single-arm feasibility study was conducted to evaluate the safety and feasibility of a novel implantable device for the treatment of OSA.

Four Ethics Committee-approved investigational centers in Germany, Canada, and the Czech Republic were involved. All site personnel were trained before the study, including implantation training in cadavers if necessary. Administrative staff were instructed in proper data collection, storage, and study procedures. The study was conducted in conformance with the Declaration of Helsinki and the laws and regulations of the participating country, whichever afforded the greater protection to the human subject. 


\section{Patient selection}

Study candidates were recruited from the investigators' clinical practices and through referrals and advertising. Subjects gave their full written informed consent prior to any study activities. Appropriate subjects were adults with moderate-to-severe OSA (defined as an Apnea-Hypopnea index [AHI] of $>15$ events $/ \mathrm{h}$ to $\leq 40$ events $/ \mathrm{h}$ ) who had previously refused or failed treatment with CPAP. To maximize the generalizability of the study, no subjects were excluded on the basis of ethnicity or other demographic factors. Key inclusion/exclusion criteria are listed in Table 1. Subjects received reimbursement for travel-related expenses as required.

\section{Device and treatment}

The implant is a linear silicone elastic element with polyesterreinforced loops on each end. At implantation, the elastic element of the implant is held in its extended state by an external sheath of poly(lactide-co-glycolide) bioabsorbable polymer. A radio-opaque marker at each end of the implant allows fluoroscopic visualization if desired. Subjects are placed briefly under general anesthesia for the procedure. Two palate implants are placed through a curved trocar using an intraoral approach, and two tongue implants are placed through a straight trocar using a submental approach (Figure 1). Softpalate placement is typically through two $4 \mathrm{~mm}$-long lateral incisions at the hard palate/soft palate junction spaced $\sim 5 \mathrm{~mm}$ to the right and left of the centerline, while tongue placement typically uses a single $8-10 \mathrm{~mm}$ incision at the base of the mandible on the centerline. No incision is made inside the mouth for the tongue-base implants. Trocar insertion utilizes tactile feedback at the base of the tongue to gauge the depth of the trocar tip. The first implant is placed along the midline adjacent to the raphe of the tongue parallel to the mandible line, terminating in the submucosa just above the vallecula. The second implant is placed along the midline adjacent to the opposite side of the raphe and terminating in the submucosa
$2-3 \mathrm{~cm}$ above the first implant. The surgical procedure also includes the optional use of X-ray imaging in the lateral and anterior-posterior directions to assist the placement of the tongue trocars as well as verification of the implant position. Preoperative antiseptic oral rinse, prophylactic antibiotics, and postoperative antibiotics (5-7 days) were administered along with appropriate wound care.

After implantation, normal healing anchors the loop ends into the target tissue. The poly(lactide-co-glycolide) formulation is a bioabsorbable material that dissolves within a few weeks and only after acute healing has occurred, allowing the elastic elements to contract and stabilize the tissue between the anchor sites. During sleep-disordered breathing, this support is intended to maintain patency of the airway by preventing the collapse of the tongue base and supporting the soft palate. Because the implants are flexible, they are expected to be compliant with normal function of the target tissue, eg, swallowing and speech.

\section{Study schedule}

Study eligibility was confirmed via baseline physical/ otolaryngological examination and standard polysomnographic parameters. Surgical procedural times were recorded. Subjects recorded their daily pain ratings (on a standard $10 \mathrm{~cm}$ Visual Analog Scale [VAS]), diet modifications, and pain medication use for the 30 days following implantation. Adverse events (AEs) were managed according to standard care at the study centers and categorized for reporting according to their intensity, relatedness to the device or procedure, outcome, and treatment or action taken. Problems with speaking, swallowing, or breathing were assessed by physician interview, airway examination, and assessment for AEs at each study visit. Reported here are feasibility and safety data from the implant procedure through 30 days post procedure in order to characterize the acute performance and results. Effectiveness outcomes will be presented in a subsequent report.

Table I Inclusion and exclusion criteria

\begin{tabular}{|c|c|}
\hline Key inclusion criteria & Key exclusion criteria \\
\hline Moderate-to-severe sleep apnea with $\mathrm{AHI}$ between $\mathrm{I} 5$ and 40 & $\begin{array}{l}\text { Prior OSA surgery (including investigational devices) except full/partial } \\
\text { tonsillectomy, adenoidectomy, and nasal surgery }\end{array}$ \\
\hline Evidence of airway collapse at the soft palate and/or base of the tongue & Enlarged tonsils $(3+$ and $4+)$ \\
\hline Between 18 years and 65 years of age & $\begin{array}{l}\text { Anatomy of the oral cavity, tongue, or soft palate unable to } \\
\text { accommodate the implant }\end{array}$ \\
\hline Body mass index $(\mathrm{BMI}) \leq 32 \mathrm{~kg} / \mathrm{m}^{2}$ & $\begin{array}{l}\text { Significant rhinitis/nasal obstruction, dysphagia, or major pulmonary } \\
\text { disorders including COPD and uncontrolled asthma }\end{array}$ \\
\hline Subjects must have been offered CPAP and refused or failed to continue & Pregnant or breastfeeding \\
\hline
\end{tabular}

Abbreviations: OSA, obstructive sleep apnea; AHI, Apnea-Hypopnea index; COPD, Chronic Obstructive Pulmonary Disease; CPAP, continuous positive airway pressure. 


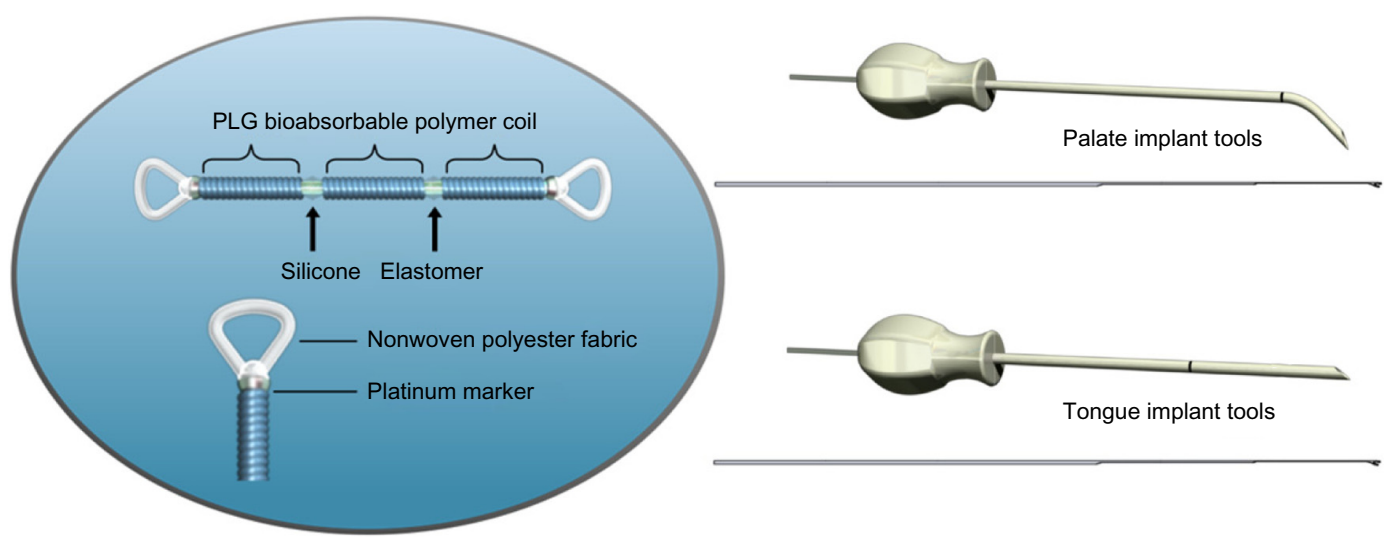

Figure I Implants and delivery tools.

Abbreviation: PLG, poly(lactide-co-glycolide).

\section{Data management and statistical analysis}

Study data were recorded and stored in compliance with local regulations and were periodically monitored by the study sponsor for quality and completeness. Procedures to prevent compromise of subject confidentiality were employed. Because this was a "first-in-man" trial of a novel device, implantations of ten-subject cohorts were completed and assessed for the feasibility of the implant procedure and any complications before proceeding to implantations of the next ten-subject cohort. Descriptive statistics were calculated. Unless otherwise noted, data are expressed as mean \pm standard error of the mean.

\section{Results}

\section{Subjects}

Forty subjects received implants between May 2011 and February 2013. There were 37 men (92.5\%) and three women (7.5\%). All subjects were Caucasian. The mean age at procedure was 46.1 years, with a range of 25-65 years. Mean baseline body mass index (BMI) was $28.3 \mathrm{~kg} / \mathrm{m}^{2}$, with a protocol deviation granted by the study sponsor for enrollment of one subject whose BMI of $32.7 \mathrm{~kg} / \mathrm{m}^{2}$ slightly exceeded the inclusion criterion of $32 \mathrm{~kg} / \mathrm{m}^{2}$. OSA-relevant characteristics (ie, palate rating, tongue size, modified Mallampati [MMP] score, tonsillar grade, neck circumference, and soft palate length) were recorded to allow analysis of response and complication rates as a function of these characteristics (Table 2).

\section{Procedural feasibility}

Each subject received two tongue-base implants and two soft-palate implants. The mean surgical time was 43 minutes (range: 21-110 minutes), which included the time needed for
Table 2 Baseline demographics

\begin{tabular}{|c|c|c|c|}
\hline Descriptor & Category & Number & $\%$ \\
\hline$N$ & Total & 40 & \\
\hline \multirow[t]{2}{*}{ Sex } & Male & 37 & 92.5 \\
\hline & Female & 3 & 7.5 \\
\hline Ethnicity & White & 40 & 100 \\
\hline \multirow[t]{2}{*}{ Palate rating $(\mathrm{N}=38)$} & Inflammation & 3 & 7.9 \\
\hline & No inflammation & 35 & 92 \\
\hline \multirow[t]{4}{*}{ Tongue size $(\mathrm{N}=34)$} & Normal & 3 & 8.8 \\
\hline & Mild & 12 & 35.2 \\
\hline & Moderate & 17 & 50 \\
\hline & Severely large & 2 & 5.8 \\
\hline \multirow[t]{3}{*}{ MMP score $(\mathrm{N}=39)$} & Class I & 7 & 17.9 \\
\hline & Class 2 & 16 & 41 \\
\hline & Class 3 & 16 & 41 \\
\hline \multirow[t]{3}{*}{ Tonsillar grade $(\mathrm{N}=38)$} & 0 & 14 & 36.8 \\
\hline & $\mathrm{I}+$ & 20 & 52.6 \\
\hline & $2+$ & 4 & 10.5 \\
\hline \multirow[t]{4}{*}{ Age } & Mean & 46.1 & \\
\hline & SEM & 1.7 & \\
\hline & Median & 45 & \\
\hline & Range & $25-65$ & \\
\hline \multirow[t]{4}{*}{ BMI, kg/m² } & Mean & 28.2 & \\
\hline & SEM & 0.5 & \\
\hline & Median & 28.6 & \\
\hline & Range & $21.3-32.7$ & \\
\hline \multirow{4}{*}{$\begin{array}{l}\text { Neck circumference, } \\
\mathrm{cm}(\mathrm{N}=30)\end{array}$} & Mean & 40.7 & \\
\hline & SEM & 0.5 & \\
\hline & Median & 40.5 & \\
\hline & Range & $35.0-46.0$ & \\
\hline \multirow{4}{*}{$\begin{array}{l}\text { Soft palate length, } \\
\mathrm{mm}(\mathrm{N}=38)\end{array}$} & Mean & 36.1 & \\
\hline & SEM & 0.6 & \\
\hline & Median & 35.5 & \\
\hline & Range & $27.0-45.0$ & \\
\hline
\end{tabular}

Abbreviations: SEM, standard error of mean; BMI, body mass index; MMP, modified Mallampati. 


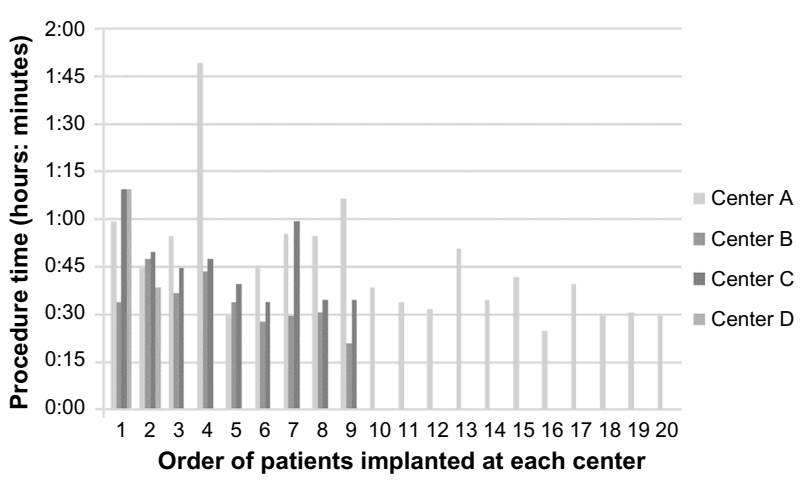

Figure 2 Surgical procedure time at different centers.

Note: Surgical procedure time averaged 43 minutes; duration of surgery decreased with the number of procedures performed.

anesthesia induction and fluoroscopic imaging. There was a trend at each of the study centers for early procedures to be lengthier than the procedures performed after some practice (Figure 2). Early procedures involved increased positioning of trocars and evaluation of implant position with fluoroscopic imaging for future evaluation of implant position versus the therapeutic effect of the implants. Later procedures continued to include fluoroscopic evaluation of implant positioning but contained fewer incidence of repositioning of the implant trocar, which was responsible for much of the procedure time decrease.

\section{Complications and adverse events Postoperative pain}

Of the 40 subjects, 36 completed a pain diary for the 30 days following the implantation procedure. Thirty-two subjects (89\%) reported diet modifications, employing a soft diet for 7.8 days $( \pm 0.8)$. Twenty-nine subjects $(81 \%)$ reported using pain medications for an average of 6.9 days $( \pm 0.9)$. All subjects reported some procedure-related pain $(>0)$. Immediately after the procedure (day 1 ), the average pain rating was 5.9 out of 10 . The severe acute pain of one subject necessitated overnight hospital admission; it resolved without sequelae. In general, pain rapidly resolved, with 30 subjects (83\%) reporting pain at day 10 (average of 2.8) and seven subjects (19\%) reporting pain at day 30 (average of 1.6; Table 3).

\section{Adverse events}

There were 94 AEs among 40 subjects. Seventy-four AEs were determined to be related to the device or procedure. A majority of AEs were the expected sequelae of a minor surgical procedure with general anesthesia and were mild.
Table 3 Pain, diet modification, and pain medication usage reported by most subjects in the immediate postoperative period

\begin{tabular}{|c|c|c|c|c|c|}
\hline $\begin{array}{l}\text { Sequelae of } \\
\text { procedure }\end{array}$ & $\begin{array}{l}\text { Number } \\
\text { of subjects } \\
\text { experiencing }\end{array}$ & $\%$ & $\begin{array}{l}\text { Mean number } \\
\text { of days } \\
\text { experienced }\end{array}$ & SEM & Range \\
\hline Diet modifications & 32 & 89 & 7.78 & 0.84 & $\mathrm{I}-20$ \\
\hline Pain medication & 29 & 81 & 6.86 & 0.90 & $1-22$ \\
\hline Had any pain & 36 & 100 & 19.08 & 1.36 & $3-30$ \\
\hline $\begin{array}{l}\text { Pain intensity, } \\
\text { by postoperative } \\
\text { day }\end{array}$ & $\begin{array}{l}\text { No. of } \\
\text { subjects } \\
\text { reporting pain } \\
(\text { VAS }>0)\end{array}$ & $\%$ & $\begin{array}{l}\text { Pain VAS } \\
\text { score, mean }\end{array}$ & SEM & Range \\
\hline Day I & 36 & 100 & 5.86 & 0.39 & $1-10$ \\
\hline Day 5 & 33 & 92 & 4.03 & 0.41 & I-9 \\
\hline Day 10 & 30 & 83 & 2.80 & 0.27 & $1-6$ \\
\hline Day 20 & 19 & 53 & 1.89 & 0.30 & $\mathrm{I}-5.5$ \\
\hline Day 30 & 7 & 19 & 1.57 & 0.35 & $0.5-3$ \\
\hline
\end{tabular}

Note: Pain largely resolved by 30 days post implantation. Abbreviations: SEM, standard error of mean; VAS, Visual Analog Scale.

One event, postsurgical pain that necessitated an inpatient night for observation after implantation, was categorized as a serious adverse event, although its severity was rated as mild.

Two subjects each had one of their tongue-base implants removed; both removals were considered serious adverse events. In one case, the subject removed an implant by himself by manually exploring the submental implant track and pulling on the implant. The site was inspected by the investigator, closed, and resolved without sequelae. In the second case, the subject developed an infection that necessitated explantation and was resolved with a course of antibiotics.

Twelve subjects experienced the extrusion of at least one soft-palate implant. Ten subjects each had one of their softpalate implants removed, and two subjects required trimming of the implant due to extrusion of the implant end into the airway. All events resolved without sequelae.

Removal of tongue and palate implants typically took just a few minutes under local anesthesia and was without difficulty in all instances. Most removals were performed through the initial incision site. The removal process included access of the implant through the incision, freeing the exposed implant loop from tissue, grasping the exposed implant end with forceps, and removing the implant by pulling on the implant loop to stretch and remove the implant. In cases where the opposite implant end was healed and anchored on to the tissue, the implant was removed by grasping the implant loop with forceps near the incision site, pulling on the implant loop to stretch the elastic implant, dissecting along the length of the implant body with surgical scissors toward the opposite end, and trimming near that 
implant end, the opposite loop, or the tissue attachment through the loop to remove most or all of the implant. Revision of the tissue surrounding the implant was performed if necessary before closure of the incision site. In all cases, patient symptoms completely and quickly resolved after implant removal.

The device was well tolerated in subjects; no AEs regarding effects on speaking, swallowing, or detrimental effect on breathing were reported, despite specific queries for these events (Table 4). Effectiveness outcomes, which will be presented in an upcoming report, included overnight polysomnographic studies at 6-monthly intervals, which will further characterize change in sleep-disordered breathing. Furthermore, the implanter system and the implants functioned as intended during the implantation procedure and did not break or malfunction.

\section{Discussion}

The demographics of the subjects enrolled in this study were representative of the OSA patients treated at the referring clinics in terms of age and sex, although it is noted that the proportion of women in this study $(7.5 \%)$ was smaller than the prevalence in the general population (up to 15\%), a fact that is nevertheless complicated by the fact that women are

Table 4 Summary of complications

\begin{tabular}{|c|c|c|}
\hline \multirow[t]{2}{*}{ Events in subjects $(n=40)$} & Total AEs & 94 \\
\hline & Total SAEs & 3 \\
\hline \multirow[t]{3}{*}{$A E$ severity } & Mild & 62 \\
\hline & Moderate & 26 \\
\hline & Severe & 6 \\
\hline AEs related to the device: inflammatory & Total & 31 \\
\hline reaction to suture, inflammation, swelling, & Remotely & 5 \\
\hline hematoma, pain, re-suturing of the incision & Possibly & 14 \\
\hline $\begin{array}{l}\text { wound, implant migration, implant protrusion/ } \\
\text { extrusion/exposure, extraction of the implant }\end{array}$ & Probably & 12 \\
\hline AEs related to the procedure: inflammation, & Total & 43 \\
\hline infection, swelling, pain, bruising, hematoma, & Remotely & 2 \\
\hline oral petechia, re-suturing of the incision wound, & Possibly & 20 \\
\hline suture clip removal, implant migration, implant & Probably & 21 \\
\hline protrusion/extrusion/exposure, extraction & & \\
\hline of the implant & & \\
\hline \multirow[t]{2}{*}{ Malfunctions } & Implants & 0 \\
\hline & $\begin{array}{l}\text { Surgical implanting } \\
\text { tools }\end{array}$ & 0 \\
\hline \multirow{4}{*}{$\begin{array}{l}\text { AEs involving disruption of normal function of } \\
\text { target tissue }\end{array}$} & & \\
\hline & Impaired speaking & 0 \\
\hline & Impaired swallowing & 0 \\
\hline & Impaired breathing & 0 \\
\hline \multirow[t]{2}{*}{ Surgical revisions of the implant required } & Tongue base $(\mathrm{N}=40)$ & 2 \\
\hline & Soft palate $(N=40)$ & 12 \\
\hline
\end{tabular}

less likely to be diagnosed and aggressively treated. ${ }^{42}$ This study excluded most obese participants because of the selection criteria taking into account the historically reported low efficacy rates of surgical interventions in the higher BMI population. ${ }^{43}$ In particular, feedback from surgeons indicated that subjects with lower BMI, small tonsils/absence of lingual tonsils, and no major palate contribution were the ideal candidates in regard to the surgical implantation procedure. The surgical time required for the implantation procedure was short. As would be expected for a "first-in-man procedure", the procedure times were related to the experience of the implanting physician. Surgeons noted that a considerable portion of the surgical time involved fluoroscopic visualization and consideration of optimal implant placement. Revised implanter tools have been released for the next-generation iteration of the device; this is expected to reduce procedural times by eliminating the need for X-ray guidance. Procedure time is also expected to decrease with continued experience, improved tooling, and fewer evaluations performed for study purposes, although it will vary among the institutions; for example, teaching hospitals may have longer procedure times to instruct and train additional staff.

The device was well tolerated by subjects in this study. The postoperative pain was moderate and well within the lower range expected for ablative procedures. ${ }^{44}$ Pain diminished considerably during the 30 -day postoperative period assessed, with the average duration of soft-food diet modifications and pain medications being $\sim 7$ days. The majority of AEs were expected and mild. The rate of extrusion of tongue-base implants was low and, although the rate of infection was $5 \%$, the overall risk of infection may be lower with this approach as compared to other OSA surgeries because no intraoral incision is required to place the tongue implants. The risk profile with this intervention is similar to or better than with other implants for the tongue (complication rates of $15 \%-30 \%$ for tongue-base suspension and $0 \%-33 \%$ for tongue-base suspension with uvulopalatopharyngoplasty, and $\sim 25 \%$ for mandible tethering) and has a lower morbidity profile than other more invasive surgical methods, although it is recognized that the rate of complications and long-term negative consequences of surgical interventions for OSA is poorly characterized. ${ }^{45-47}$ Thus, the risks with this novel implant are considered to be acceptable as compared to other surgical approaches treating sleep apnea. Lastly, and perhaps most importantly, no subjects reported instances of foreign-body sensation, swallowing insufficiency, tongue mobility effects, or speech impediments, unlike with other procedures. ${ }^{35,48}$ In fact, investigators anecdotally report that 
some subjects have relayed having had no awareness of the implant whatsoever, after the healing process. Overnight polysomnographic studies were conducted in these subjects at baseline and at 6-monthly intervals to measure changes in sleep-disordered breathing; data will be presented in the upcoming effectiveness paper.

Unfortunately, there was a high incidence of device extrusions in the soft palate. Such events have been observed with other palate implants with an occurrence of $\sim 9 \%$, likely due to the thinness of the palate mucosal tissue. ${ }^{26,49}$ Although extruding implants were readily addressed with minor procedures to remove or trim the implants, palate implants have been eliminated from the next-generation product configuration, which focuses only on tongue implants. Thus, physicians may perform their preferred procedure for addressing palate-level closure in those patients who require it.

It was noted during the study that two implants in the tongue base appeared insufficient to provide optimal tongue coverage for some subjects. Future studies would involve four implants placed along the midline of the tongue axially adjacent to one another to span a broader area of the tongue base with potentially greater effectiveness at preventing closure. Effectiveness outcomes will be presented in a subsequent report.

\section{Conclusion}

In this report, we presented the first human data for a firstgeneration sleep apnea system and placement procedure designed to treat OSA, a multifactorial, multilevel condition. The minimally invasive nature of the novel implants and their delivery were chosen instead of other more invasive or destructive and irreversible ablative options. The device and implantation tools were demonstrated to be feasible; the reported post-implantation issues (eg, palate extrusions) were due to issues with implant location/depth, placement of device, or infection, rather than device failures per se. The implant is believed to stabilize the tongue base and soft palate to increase the airway caliber and thus decrease the degree of airway collapse during sleep. The feasibility/usability data in this report demonstrates that this device has a safety profile that is favorable compared to other available treatments for tongue-base OSA, such as surgical remodeling of the airway. The tongue implant was well tolerated with no foreign-body sensation or difficulties with speech or swallowing, thus validating the design concept for the device. The soft-palate implant extruded at a significant frequency, and therefore will require technical adaptations and has been discontinued for the near term. Although the study's conclusions are limited by its single-arm design and sample size, this clinical series provides early indications of the system's safety and appropriateness for the treatment of tongue-base OSA. Future reports will present clinical effectiveness via comparison of pre- and post-treatment outcome measures.

\section{Acknowledgment}

This study was sponsored by ReVENT Medical, Inc. The intellectual contribution of Dr Allison Foster is acknowledged for professional medical writing assistance.

\section{Disclosure}

VP, BR, JTM, and TV received compensation as clinical investigators for this study. EG is a founder of ReVENT Medical, Inc. In addition, JTM and TV received honoraria for leading a training course for the ReVENT technique. The authors report no other conflicts of interest in this work.

\section{References}

1. Teschler H, Randerath W. Sleep-related breathing disorders historical development, current status, future prospects. Pneumologie. 2010;64(9):583-589.

2. Green DE, Schulman DA. Obstructive sleep apnea and cardiovascular disease. Curr Treat Options Cardiovasc Med. 2010;12(4):342-354.

3. Peker Y, Hedner J, Kraiczi H, Loth S. Respiratory disturbance index: an independent predictor of mortality in coronary artery disease. $\mathrm{Am} \mathrm{J}$ Respir Crit Care Med. 2000;162(1):81-86.

4. Young T, Finn L, Peppard PE, et al. Sleep disordered breathing and mortality: eighteen-year follow-up of the Wisconsin sleep cohort. Sleep. 2008;31(8):1071-1078.

5. Young T, Palta M, Dempsey J, Skatrud J, Weber S, Badr S. The occurrence of sleep-disordered breathing among middle-aged adults. N Engl J Med. 1993;328(17):1230-1235.

6. Jenkinson C, Davies RJ, Mullins R, Stradling JR. Comparison of therapeutic and subtherapeutic nasal continuous positive airway pressure for obstructive sleep apnoea: a randomised prospective parallel trial. Lancet. 1999;353(9170):2100-2105.

7. Hack M, Davies RJ, Mullins R, et al. Randomised prospective parallel trial of therapeutic versus subtherapeutic nasal continuous positive airway pressure on simulated steering performance in patients with obstructive sleep apnoea. Thorax. 2000;55(3):224-231.

8. Calhoun DA, Harding SM. Sleep and hypertension. Chest. 2010; 138(2):434-443.

9. Redline S, Yenokyan G, Gottlieb DJ, et al. Obstructive sleep apneahypopnea and incident stroke: the sleep heart health study. Am J Respir Crit Care Med. 2010;182(2):269-277.

10. Gottlieb DJ, Whitney CW, Bonekat WH, et al. Relation of sleepiness to respiratory disturbance index: the Sleep Heart Health Study. Am J Respir Crit Care Med. 1999;159(2):502-507.

11. Yaggi HK, Concato J, Kernan WN, Lichtman JH, Brass LM, Mohsenin V. Obstructive sleep apnea as a risk factor for stroke and death. $N \mathrm{Engl}$ J Med. 2005;353(19):2034-2041.

12. Punjabi NM, Caffo BS, Goodwin JL, et al. Sleep-disordered breathing and mortality: a prospective cohort study. PLoS Med. 2009;6(8):e1000132.

13. Ram S, Seirawan H, Kumar SK, Clark GT. Prevalence and impact of sleep disorders and sleep habits in the United States. Sleep Breath. 2010;14(1):63-70.

14. Kapur VK, Alfonso-Cristancho R. Just a good deal or truly a steal? Medical cost savings and the impact on the cost-effectiveness of treating sleep apnea. Sleep. 2009;32(2):135-136. 
15. Rama AN, Tekwani SH, Kushida CA. Sites of obstruction in obstructive sleep apnea. Chest. 2002;122(4):1139-1147.

16. Buchner NJ, Sanner BM, Borgel J, Rump LC. Continuous positive airway pressure treatment of mild to moderate obstructive sleep apnea reduces cardiovascular risk. Am J Respir Crit Care Med. 2007;176(12):1274-1280.

17. Grote L, Hedner J, Grunstein R, Kraiczi H. Therapy with nCPAP: incomplete elimination of sleep related breathing disorder. Eur Respir J. 2000;16(5):921-927.

18. Weaver TE, Grunstein RR. Adherence to continuous positive airway pressure therapy: the challenge to effective treatment. Proc Am Thorac Soc. 2008;5(2):173-178.

19. Kribbs NB, Pack AI, Kline LR, et al. Objective measurement of patterns of nasal CPAP use by patients with obstructive sleep apnea. Am Rev Respir Dis. 1993;147(4):887-895.

20. Phillips CL, Grunstein RR, Darendeliler MA, et al. Health outcomes of continuous positive airway pressure versus oral appliance treatment for obstructive sleep apnea: a randomized controlled trial. Am J Respir Crit Care Med. 2013;187(8):879-887.

21. Walker-Engstrom M-L, Tegelberg A, Wilhelmsson B, Ringqvist I. 4-year follow-up of treatment with dental appliance or uvulopalatopharyngoplasty in patients with obstructive sleep apnea: a randomized study. Chest. 2002;121:739-746.

22. Maurer JT. Surgical treatment of obstructive sleep apnea: standard and emerging techniques. Curr Opin Pulm Med. 2010;16(6):552-558.

23. Kezirian EJ. Hypopharyngeal surgery in obstructive sleep apnea: an evidence-based medicine review. JAMA Otolaryngol Head Neck Surg. 2006;132(2):206-213.

24. Baradaranfar MH, Edalatkhah M, Dadgarnia MH, et al. The effect of uvulopalatopharyngoplasty with tonsillectomy in patients with obstructive sleep apnea. Indian J Otolaryngol Head Neck Surg. 2015;67(suppl 1): 29-33.

25. Friedman M, Schalch P, Lin HC, Kakodkar KA, Joseph NJ, Mazloom N. Palatal implants for the treatment of snoring and obstructive sleep apnea/hypopnea syndrome. Otolaryngol Head Neck Surg. 2008;138(2):209-216.

26. Choi JH, Kim S-N, Cho JH. Efficacy of the pillar implant in the treatment of snoring and mild-to-moderate obstructive sleep apnea: a metaanalysis. Laryngoscope. 2013;123(1):269-276.

27. Hamans E, Boudewyns A, Stuck BA, et al. Adjustable tongue advancement for obstructive sleep apnea: a pilot study. Ann Otol Rhinol Laryngol. 2008;117(11):815-823.

28. Woodson BT, Steward DL, Mickelson S, Huntley T, Goldberg A. Multicenter study of a novel adjustable tongue-advancement device for obstructive sleep apnea. Otolaryngol Head Neck Surg. 2010;143(4):585-590.

29. van Maanen JP, Witte BI, de Vries N. Theoretical approach towards increasing effectiveness of palatal surgery in obstructive sleep apnea: role for concomitant positional therapy? Sleep Breath. 2014;18:341-349.

30. Tan KB, Toh ST, Guilleminault C, Holty J-EC. A cost-effectiveness analysis of surgery for middle-aged men with severe obstructive sleep apnea intolerant of CPAP. J Clin Sleep Med. 2015;11(5): $525-535$.

31. Boyd SB, Walters AS, Song Y, Wang L. Comparative effectiveness of maxillomandibular advancement and uvulopalatopharyngoplasty for the treatment of moderate to severe obstructive sleep apnea. J Oral Maxillofac Surg. 2013;71(4):743-751.

Nature and Science of Sleep

\section{Publish your work in this journal}

Nature and Science of Sleep is an international, peer-reviewed, open access journal covering all aspects of sleep science and sleep medicine, including the neurophysiology and functions of sleep, the genetics of sleep, sleep and society, biological rhythms, dreaming, sleep disorders and therapy, and strategies to optimize healthy sleep. The journal welcomes
32. Handler E, Hamans E, Goldberg AN, Mickelson S. Tongue suspension: an evidence-based review and comparison to hypopharyngeal surgery for OSA. Laryngoscope. 2014;124:329-336.

33. Caples SM, Rowley JA, Prinsell JR, et al. Surgical modifications of the upper airway for obstructive sleep apnea in adults: a systematic review and meta-analysis. Sleep. 2010;33(10):1396-1407.

34. Baba RY, Mohan A, Metta VV, Mador MJ. Temperature controlled radiofrequency ablation at different sites for treatment of obstructive sleep apnea syndrome: a systematic review and meta-analysis. Sleep Breath. 2015;19:891-910.

35. Franklin KA, Anttila H, Axelsson S, et al. Effects and side-effects of surgery for snoring and obstructive sleep apnea - a systematic review. Sleep. 2009;32(1):27-36.

36. Sundaram S, Lim J, Lasserson TJ, Bridgman SA. Surgery for obstructive sleep apnea. Cochrane Database Syst Rev. 2005;19(4):CD001004.

37. Pang KP, Siow JK, Tseng P. Safety of multilevel surgery in obstructive sleep apnea: a review of 487 cases. Arch Otolaryngol Head Neck Surg. 2012;138(4):353-357.

38. Fouladpour N, Jesudoss R, Bolden N, Shaman Z, Auckley D. Perioperative complications in obstructive sleep apnea patients undergoing surgery: a review of the legal literature. Anesth Analg. 2016;122(1):145-151.

39. Nelson RE, Carter JM, Anand AG. Hypopharyngeal airway surgery for obstructive sleep apnea: morbidity in the early postoperative period. Otolaryngol Head Neck Surg. 2014;151(1 suppl):260-261.

40. Li KK, Riley RW, Powell NB, Gervacio L, Troell RJ, Minault C. Obstructive sleep apnea surgery: patient perspective and polysomnographic results. Otolaryngol Head Neck Surg. 2000;123:572-575.

41. Gillis E, Rampersaud C, Pease E, Buscemi P. A novel implantable device for a minimally invasive surgical treatment of obstructive sleep apnea: design and preclinical safety assessment. Nat Sci Sleep. In press.

42. Young T, Skatrud J, Peppard PE. Risk factors for obstructive sleep apnea in adults. JAMA. 2004;291(16):2013-2016.

43. Jordan AS, McSharry DG, Malhotra A. Adult obstructive sleep apnea. Lancet. 2014;383(9918):736-747.

44. Blumen MB, Chalumeau F, Gauthier A, Bobin S, Coste A, Chabolle F. Comparative study of four radiofrequency generators for the treatment of snoring. Otolaryngol Head Neck Surg. 2008;138:294-299.

45. Bostanci A, Turhan M. A systematic review of tongue base suspension techniques as an isolated procedure or combined with uvulopalatopharyngoplasty in obstructive sleep apnea. Eur Arch Otorhinolaryngol. Epub 2015 Oct 27.

46. Pavelec V, Hamans E, Stuck BA. A study of the new generation of the advance system tongue implants: three- and six-month effects of tongue to mandible tethering for obstructive sleep apnea. Laryngoscope. 2011;121:2487-2493.

47. Aurora RN, Casey KR, Kristo D, et al; American Academy of Sleep Medicine. Practice parameters for the surgical modifications of the upper airway for obstructive sleep apnea in adults. Sleep. 2010;33(10):1408-1413.

48. Stuck BA, Sauter A, Hormann K, Verse T, Maurer JT. Radiofrequency surgery of the soft palate in the treatment of snoring. A placebocontrolled trial. Sleep. 2005;28(7):847-850.

49. Friedman M, Vidyasagar R, Bliznikas D, Joseph NJ. Patient selection and efficacy of pillar implant technique for treatment of snoring and obstructive sleep apnea/hypopnea syndrome. Otolaryngol Head Neck Surg. 2006;134:187-196.

\section{Dovepress}

original research, clinical \& epidemiological studies, reviews \& evaluations, case reports and extended reports. The manuscript management system is completely online and includes a very quick and fair peerreview system, which is all easy to use. Visit http://www.dovepress.com/ testimonials.php to read real quotes from published authors. 